\title{
Undergraduate Teaching in Geriatrics and Pediatrics in Portuguese Medical Schools: An Observational Study
}

\author{
Formação Pré-Graduada em Geriatria e Pediatria no \\ Ensino Médico Português: Um Estudo Observacional
}

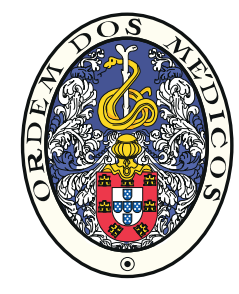

Mariana AMARAL $\triangle^{1}$, Filipa MATIAS ${ }^{2}$, Lígia MASSENA ${ }^{3}$, Nuno CARDOSO ${ }^{4}$

Acta Med Port 2016 Dec;29(12):832-838 - http://dx.doi.org/10.20344/amp.8380

\section{ABSTRACT}

Introduction: Motivated by the contracting nature of the Portuguese age pyramid, and thereby the ever increasing geriatric population, the aim of this study was to compare the number of European Credit Transfer and Accumulation System Credits dedicated to Geriatrics with Pediatrics in Portuguese Medical Schools.

Material and Methods: An observational, descriptive and cross-sectional study was conducted and included six Portuguese Medical Schools that have six years of training and a total of 360 credits. The study plans were obtained from the medical schools' websites or requested. Schools were grouped in modular/classic teaching methodology and the courses were categorized in mandatory/optional and specific/related. The credits of Geriatrics and Pediatrics were compared.

Results: Four schools had classical methodology and two had a modular one. Overall, they had more credits dedicated to Pediatrics than Geriatrics. Three schools offered mandatory courses specifically oriented to Geriatrics ( $1.5-8$ credits) compared to all schools mandatory courses courses on Pediatrics (5.7 - 26.5 credits). The ratio of averages of mandatory specific courses (Pediatrics/Geriatrics) was 12.4 in the classical and 1.5 in the modular group.

Discussion: Pediatrics teaching has revealed to be superior to Geriatrics in all categories. Based on our results, we consider the Portuguese Geriatrics' undergraduate teaching sub-optimal.

Conclusion: Nowadays, geriatric population is quantitatively similar to pediatric population. Efforts should be made to adequate Geriatrics teaching to our reality in order to provide a more adequate health care to this age group.

Keywords: Curriculum; Education, Medical, Undergraduate; Geriatrics/education; Pediatrics/education; Portugal; Schools, Medical.

\section{RESUMO}

Introdução: Motivados pelo aumento do número de idosos em Portugal, propusemo-nos a comparar o número de créditos atribuídos a Geriatria e a Pediatria pelo Sistema Europeu de Transferência de Créditos nas Escolas Médicas Portuguesas.

Material e Métodos: Estudo observacional, descritivo e transversal incluindo seis Escolas Médicas com seis anos de formação e um total de 360 créditos. Os dados foram colhidos em março e abril de 2016, dos sítios da Internet das faculdades ou pedidos quando não disponibilizados. As Escolas foram divididas pela metodologia de ensino (clássica/modular) e as disciplinas por categorias (obrigatória/ opcional e específica/relacionada). Os créditos obtidos para a Geriatria e Pediatria foram comparados.

Resultados: Das Escolas Médicas incluídas, duas tinham metodologia modular e as restantes clássica, dedicando globalmente mais créditos ao ensino de Pediatria que Geriatria. Três ofereciam cadeiras obrigatórias específicas para Geriatria (1,5 - 8 créditos), enquanto que todas ofereciam cadeiras obrigatórias específicas para Pediatria (5,7-26,5 créditos). O rácio das médias de créditos obrigatórios e específicos (Pediatria/Geriatria) foi de 12,4 nas clássicas e 1,5 nas modulares.

Discussão: Globalmente, o ensino da Pediatria é superior ao da Geriatria em todas as categorias. Através dos resultados obtidos, consideramos que o ensino pré-graduado de Geriatria em Portugal não é adequado.

Conclusão: Apesar da população geriátrica ser epidemiologicamente semelhante à pediátrica, as Escolas Médicas Portuguesas dedicam mais tempo ao ensino da Pediatria. São necessários ajustes aos planos de estudo para melhorar os cuidados de saúde prestados a este grupo populacional.

Palavras-chave: Currículo; Educação Médica Pré-Graduada; Escolas Médicas; Geriatria/educação; Pediatria/educação; Portugal.

\section{INTRODUCTION}

In line with other developed countries, Portugal presents a contracting age pyramid, characterized by an increment of life expectancy as well as a decreasing crude natality rate. In 2014, the Portuguese geriatric population (equal or over 65 years old) accounted for $20.5 \%$ and the age category from 0 to 19 years old corresponded to $19.6 \%$ of the total population. ${ }^{1}$

As the number of older people rises, along with comorbidities and disabilities, the associated health care services have to be adjusted. This age group has specific needs, which should be provided ideally by a team in different contexts, such as community and institutional care, rehabilitation facilities and hospitals. ${ }^{2}$ In order to being able to provide better care, there must be a careful planning of both undergraduate and postgraduate medical training.

Geriatrics teaching (GT) in undergraduate setting in Europe is heterogeneous. ${ }^{3}$ Some societies, such as the American Geriatrics Society and the Geriatric Section of the

\footnotetext{
1. Unidade de Saúde Familiar Covelo. Porto. Portugal.

2. Unidade de Saúde Familiar Novo Sentido. Porto. Portugal.

3. Unidade de Saúde Familiar Nova Via. Vila Nova de Gaia. Portugal.

4. Faculdade de Engenharia. Universidade do Porto. Porto. Portugal.

$\triangle$ Autor correspondente: Mariana Amaral. mrsamaral@hotmail.com

Recebido: 28 de outubro de 2016 - Aceite: 07 de dezembro de 2016 | Copyright @ Ordem dos Médicos 2016
} 
European Union of Medical Specialists have suggested core competences, skills and knowledge that should compose a Geriatrics curriculum. ${ }^{4,5}$ In a study conducted by Michel JP et al, 2008, regarding GT in 31 European countries, only six had an established chair of Geriatrics in all of their schools (Belgium, Finland, France, Iceland, Norway, and Sweden) and eight of them had no chair of Geriatric Medicine at all (Austria, Greece, Estonia, Macedonia, Moldavia, Slovenia, Luxembourg, and Malta). Unfortunately Portugal did not answer to the survey. ${ }^{3}$ In Portugal there is not a national Geriatrics curriculum, and there are not specific geriatric wards in hospitals, rehabilitation or long-term care facilities, which raises difficulties to the implementation of GT.

Geriatrics is a medical specialization in 16 European countries. ${ }^{3}$ In Portugal, a specialization or subspecialization in Geriatrics is not yet recognized by the national medical association. However, a competence in Geriatrics was started in $2014 .^{6}$ There are also postgraduate programs, including Post-Graduate, Master's and Doctoral degrees related to Geriatrics.

The pediatric and geriatric groups correspond to the two extremes of the age pyramid, and are epidemiologically similar. However, in contrast to Geriatrics, Pediatrics has suffered a robust and sustainable development worldwide. The specialty was recognized in 1944 by the Portuguese Medical Association. In addition, there are seven subspecialties dedicated to this age group.,

Since it is expected an accretion of the number of older people, Geriatrics undergraduate teaching should be encouraged and promoted, following the example of Pediatrics in the last century.

As previously stated, geriatric and pediatric populations share some particularities like, for example, approximate percentages of the total population, being at opposite extremes of the age pyramid, and both of them with differentiated special needs. With that in mind, beyond exploring the current situation in Geriatrics, we also decided to use Pediatrics as a mean of comparison. Nevertheless, Geriatrics is the main focus of our study.

We propose the hypothesis that the number of European Credit Transfer and Accumulation System Credits (ECTSs) dedicated to Pediatrics teaching (PT) is superior to Geriatrics teaching both in mandatory and optional courses in Portuguese Medical Schools (PMSs) with classic and modular teaching methodologies.

The main purpose of this study is to access the number of ECTSs presented in PMSs' study plans that are dedicated to Geriatrics and compare it to the number of ECTSs dedicated to Pediatrics.

\section{MATERIAL AND METHODS}

\section{Study sample}

We conducted an observational, descriptive and crosssectional study. We evaluated the eight PMSs for potential inclusion in the study. The established inclusion criteria were: six years of training, curriculum with a total of 360 ECTSs and access to the curricula. One was excluded because its training program had less than six years and 360 ECTSs (from Algarve University). Another one, from Lisbon University, was excluded because the institution refused to grant its curricula. A total of six PMSs were included and evaluated, corresponding to a sample of $75 \%$ of the PMSs (Fig. 1).

\section{Data sources}

We collected the data between March 2016 and April 2016. The study plans were obtained from the PMSs' websites during April 2016. We contacted the academic department of every PMS that did not have the individual courses' program in their study plans and they sent them to the investigators.

\section{Variables}

Since there are two different teaching methodologies which are not directly comparable, we grouped the PMSs accordingly and performed the analysis separately. Four of the PMSs had a classical study plan (subjects like 'anatomy' or 'physiology') and the other two had a modular plan, in which several disciplines may contribute to a major one (e.g. a subject called 'human body' includes cellular biology, anatomy, histology and physiology) (Table 1).

To evaluate the impact each course had in the corresponding curriculum, we used the courses' ECTSs. For each PMS, we divided its courses and sum the corresponding ECTSs based on two criteria: mandatory/ optional and specific/related (total of four categories).

In order to determine the specific courses, we searched for keywords in each study plan, using the Portuguese terms for: 'geriatrics', 'gerontology', 'elder', 'ageing', and 'children', 'pediatrics', 'adolescent', 'youth', 'juvenile'.

For the related courses, we assessed the presence

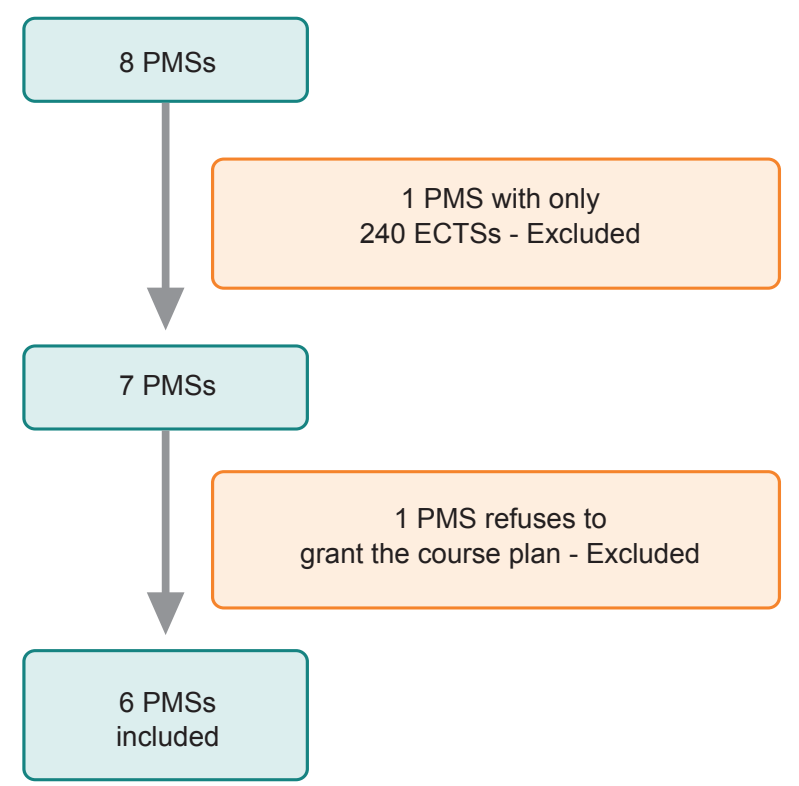

Figure 1 - Flowchart of included Portuguese Medical Schools (PMSs)

ECTSs: European Credit Transfer and Accumulation System Credits. 
Table 1 - Included Portuguese Medical Schools and respective teaching methodology

\begin{tabular}{lll}
\hline PMS & Short denomination & Study plan \\
\hline Faculdade de Medicina - Universidade de Coimbra ${ }^{9}$ & Coimbra U & Classic \\
Faculdade de Ciências Médicas - Universidade Nova de Lisboa ${ }^{10}$ & Nova U & Classic \\
Faculdade de Medicina - Universidade do Porto & Classic \\
Instituto de Ciências Biomédicas Abel Salazar - Universidade do Porto ${ }^{12}$ & Porto - FMUP & Porto - ICBAS \\
Faculdade de Ciências da Saúde - Universidade da Beira Interior ${ }^{13}$ & Beira Interior U & Modular \\
Escola de Ciências da Saúde - Universidade do Minho ${ }^{14}$ & Minho U & Modular \\
\hline
\end{tabular}

PMS: Portuguese Medical Schools; U: University

of those keywords in each courses' individual program, accounting for a related course whenever one of the mentioned keywords was found in the courses description items (e.g. if a given course had ten topics in its description and one of them included the 'geriatrics' keyword, this course will be placed in the related category).

Whenever a course had an explicit division in its study plan with a clear weight to each of its items, we only accounted for the corresponding subset of the total ECTSs (e.g. if 'woman and children health' subject had 10 ECTSs and in its plan it is specified that pediatrics accounted for $40 \%$, we accounted for 4 ECTSs).

\section{Data analysis}

From the collected data, we calculated the mean values for each group and category. The prevalence of GT and PT was calculated for mandatory courses only, subtracting the optional ECTSs that each PMS allows the students to attend from the total possible ECTSs (360). We opted not to include the optional courses in the teaching prevalence calculus, since it is possible that some students do not choose any of the geriatric or pediatric optional courses to attend during their path.
We compared Geriatrics and Pediatrics for each category within each PMS, calculating the difference between the ECTSs dedicated to Pediatrics and the ECTSs dedicated to Geriatrics, as well as their ratios. We also calculated the ratio of the averages of the mandatory specific courses. The statistical significance for the difference between geriatric and pediatric courses (for mandatory/optional and specific/ related categories, individually) was calculated, using onetailed paired sample t-test. Statistical significance was assumed for $p<0.05$ using a Confidence Interval $(\mathrm{Cl})$ of $95 \%$.

\section{RESULTS \\ Geriatrics teaching}

As shown in Table 2, only half of the PMSs had mandatory geriatric specific courses, two of them with classical and one with modular teaching methodology. On the other hand, all PMSs offered mandatory courses that include geriatric related topics in their plans.

Regarding the optional courses, in the classical group, two PMSs offered both specific and related courses, one offered only specific courses and the other one only related ones. The modular teaching PMSs did not offer optional

Table 2 - Geriatrics teaching in Portuguese Medical Schools

\begin{tabular}{|c|c|c|c|c|c|c|c|}
\hline & \multirow[b]{2}{*}{ PMS } & \multicolumn{3}{|c|}{ Mandatory (ECTSs) } & \multicolumn{3}{|c|}{ Optional (ECTSs) } \\
\hline & & $\begin{array}{l}\text { Specific } \\
\text { courses }\end{array}$ & $\begin{array}{l}\text { Related } \\
\text { courses }\end{array}$ & $\begin{array}{l}\text { Total mandatory } \\
\text { curricula }\end{array}$ & $\begin{array}{l}\text { Specific } \\
\text { courses }\end{array}$ & $\begin{array}{l}\text { Related } \\
\text { courses }\end{array}$ & $\begin{array}{l}\text { Total optional } \\
\text { curricula }\end{array}$ \\
\hline \multirow{5}{*}{$\begin{array}{l}\frac{0}{\bar{D}} \\
0 \\
\frac{\pi}{U}\end{array}$} & Coimbra U & - & $\begin{array}{c}15.5 \\
(4.6 \%)\end{array}$ & 340 & 2 & 8 & 20 \\
\hline & Nova U & $\begin{array}{c}4 \\
(1.2 \%)\end{array}$ & $\begin{array}{c}61 \\
(17.6 \%)\end{array}$ & 346 & 3 & 12 & 14 \\
\hline & Porto - FMUP & $\begin{array}{c}1.5 \\
(0.5 \%)\end{array}$ & $\begin{array}{c}13 \\
(3.9 \%)\end{array}$ & 333 & 3 & - & 27 \\
\hline & Porto - ICBAS & - & $\begin{array}{c}42 \\
(11.9 \%)\end{array}$ & 352.5 & - & 3 & 7.5 \\
\hline & Average & 1.4 & 32.9 & & 2 & 5.8 & \\
\hline \multirow{3}{*}{$\begin{array}{l}\frac{\bar{\pi}}{2} \\
\overline{\frac{D}{2}} \\
\frac{0}{2}\end{array}$} & Beira Interior $U$ & $\begin{array}{c}8 \\
(2.2 \%)\end{array}$ & $\begin{array}{c}6 \\
(1.7 \%)\end{array}$ & 360 & $\mathrm{~N} / \mathrm{A}$ & N/A & 0 \\
\hline & Minho U & - & $\begin{array}{c}10.5 \\
(2.9 \%)\end{array}$ & 360 & $\mathrm{~N} / \mathrm{A}$ & $\mathrm{N} / \mathrm{A}$ & 0 \\
\hline & Average & 4 & 8.3 & & $N / A$ & $N / A$ & \\
\hline
\end{tabular}

The trace (-) corresponds to zero; the percentage within the parenthesis corresponds to the prevalence. ECTSs: European Credit Transfer and Accumulation System Credits; N/A: Not applicable; PMS: Portuguese Medical Schools; U: University 
courses, so all of the 360 ECTSs correspond to mandatory courses.

In order to provide a more practical view, we calculated the prevalence of the mandatory teaching of Geriatrics for each PMS's plan. In the classical group, the prevalence of specific courses ranged from 0 to $1.2 \%$, and of related courses from 3.9 to $17.6 \%$. In the modular group, the prevalence of specific courses ranged from 0 to $2.2 \%$, and of related courses ranged from 1.7 to $2.9 \%$.

\section{Pediatrics teaching}

As shown in Table 3, all PMSs offered mandatory specific and related courses. Only three out of four offered both specific and related optional courses. As previously said, the modular group has not optional courses to offer.

The prevalence of the mandatory teaching of Pediatrics in the classical group for the specific courses ranged from 3.0 to $7.7 \%$, and for the related ones from 4.5 to $12.7 \%$. In the modular group, the prevalence of specific courses was $1.7 \%$, and of related courses ranged from 8.3 to $14.4 \%$.

\section{Comparison between Geriatrics teaching and Pediatrics teaching}

In order to compare the Geriatrics with Pediatrics teaching, we calculated the differences and the ratios for all courses' categories. We opted to use GT as the subtrahend and denominator, taking into consideration that PT is globally superior to GT.

For all the classical PMSs, the specific pediatric mandatory courses had a superior impact when compared to geriatric ones (ratio of averages of 12.43), with a significant statistical difference ( $p=0.004, \mathrm{Cl} 95 \%)$. Nova $U$ was an exception for the related courses - GT had more
17 ECTSs than PT, with a ratio of 0.7 , corresponding to 1.4 times the PT. Also in the optional category, PT offered a superior number of ECTSs when compared to GT, except for a superiority of 3 ECTSs in geriatric specific courses in Porto-FMUP and 2 ECTSs in geriatric related ones in Coimbra $U$ (ratio of 0.75 , corresponding to 1.3 times the PT) (Fig. 2, Table 4).

As the PMSs in the modular group do not offer the possibility to attend optional courses, we only calculated the difference and ratio for the mandatory ones. Overall, PT's specific mandatory courses were superior to GT's (ratio of averages of 1.50).

\section{DISCUSSION}

In the majority of PMSs, a higher amount of ECTSs was dedicated to Pediatrics, when compared to Geriatrics, in all courses categories. As the geriatric and pediatric population are epidemiologically comparable, we would assume that the ECTSs devoted to each one would be closer, which was not verified in our data.

To reach our main goal of comparing PT and GT, the most important subgroup is presumably the mandatory (in which we can assume that all registered students attended the courses) and specific courses (in which we can admit that all lectures were entirely dedicated to the subject). In this category, the superiority of PT was particularly noticeable in the classic PMSs with PT being over 12 times superior to GT (ratio of averages of 12.43). In modular PMSs there were less marked differences, with Beira Interior $U$ being the only PMS where GT was higher than PT (Fig. 2). Once again, it is important to emphasize that half of the PMSs did not offer any mandatory specific courses on Geriatrics. Based on the changes in Portuguese demography already explained,

Table 3 - Pediatrics teaching in Portuguese Medical Schools

\begin{tabular}{|c|c|c|c|c|c|c|c|}
\hline & \multirow[b]{2}{*}{ PMS } & \multicolumn{3}{|c|}{ Mandatory (ECTSs) } & \multicolumn{3}{|c|}{ Optional (ECTSs) } \\
\hline & & $\begin{array}{l}\text { Specific } \\
\text { courses }\end{array}$ & $\begin{array}{l}\text { Related } \\
\text { courses }\end{array}$ & $\begin{array}{l}\text { Total mandatory } \\
\text { curricula }\end{array}$ & $\begin{array}{l}\text { Specific } \\
\text { courses }\end{array}$ & $\begin{array}{l}\text { Related } \\
\text { courses }\end{array}$ & $\begin{array}{c}\text { Total optional } \\
\text { curricula }\end{array}$ \\
\hline \multirow{5}{*}{$\begin{array}{l}\frac{0}{W} \\
\mathbb{D} \\
\frac{\pi}{U}\end{array}$} & Coimbra U & $\begin{array}{c}14.5 \\
(4.3 \%)\end{array}$ & $\begin{array}{c}28.5 \\
(8.4 \%)\end{array}$ & 340 & 2 & 6 & 20 \\
\hline & Nova U & $\begin{array}{c}26.5 \\
(7.7 \%)\end{array}$ & $\begin{array}{c}44 \\
(12.7 \%)\end{array}$ & 346 & 9 & 24 & 14 \\
\hline & Porto - FMUP & $\begin{array}{c}18 \\
(5.4 \%)\end{array}$ & $\begin{array}{c}15 \\
(4.5 \%)\end{array}$ & 333 & - & - & 27 \\
\hline & Porto - ICBAS & $\begin{array}{l}10.5 \\
(3 \%)\end{array}$ & $\begin{array}{c}43 \\
(12.1 \%)\end{array}$ & 352.5 & 3 & 12 & 7.5 \\
\hline & Average & 17.4 & 32.6 & & 3.5 & 10.5 & \\
\hline \multirow{3}{*}{$\begin{array}{l}\frac{1}{\frac{\pi}{2}} \\
\frac{0}{2} \\
\frac{0}{2}\end{array}$} & Beira Interior $U$ & $\begin{array}{c}6 \\
(1.7 \%)\end{array}$ & $\begin{array}{c}30 \\
(8.3 \%)\end{array}$ & 360 & N/A & $\mathrm{N} / \mathrm{A}$ & 0 \\
\hline & Minho U & $\begin{array}{c}6 \\
(1.6 \%)\end{array}$ & $\begin{array}{c}52 \\
(14.4 \%)\end{array}$ & 360 & N/A & $\mathrm{N} / \mathrm{A}$ & 0 \\
\hline & Average & 6 & 41 & & N/A & N/A & \\
\hline
\end{tabular}

The trace (-) corresponds to zero, the percentage within the parenthesis corresponds to the prevalence. ECTSs: European Credit Transfer and Accumulation System Credits; N/A: Not applicable, PMS: Portuguese Medical Schools; U: University. 

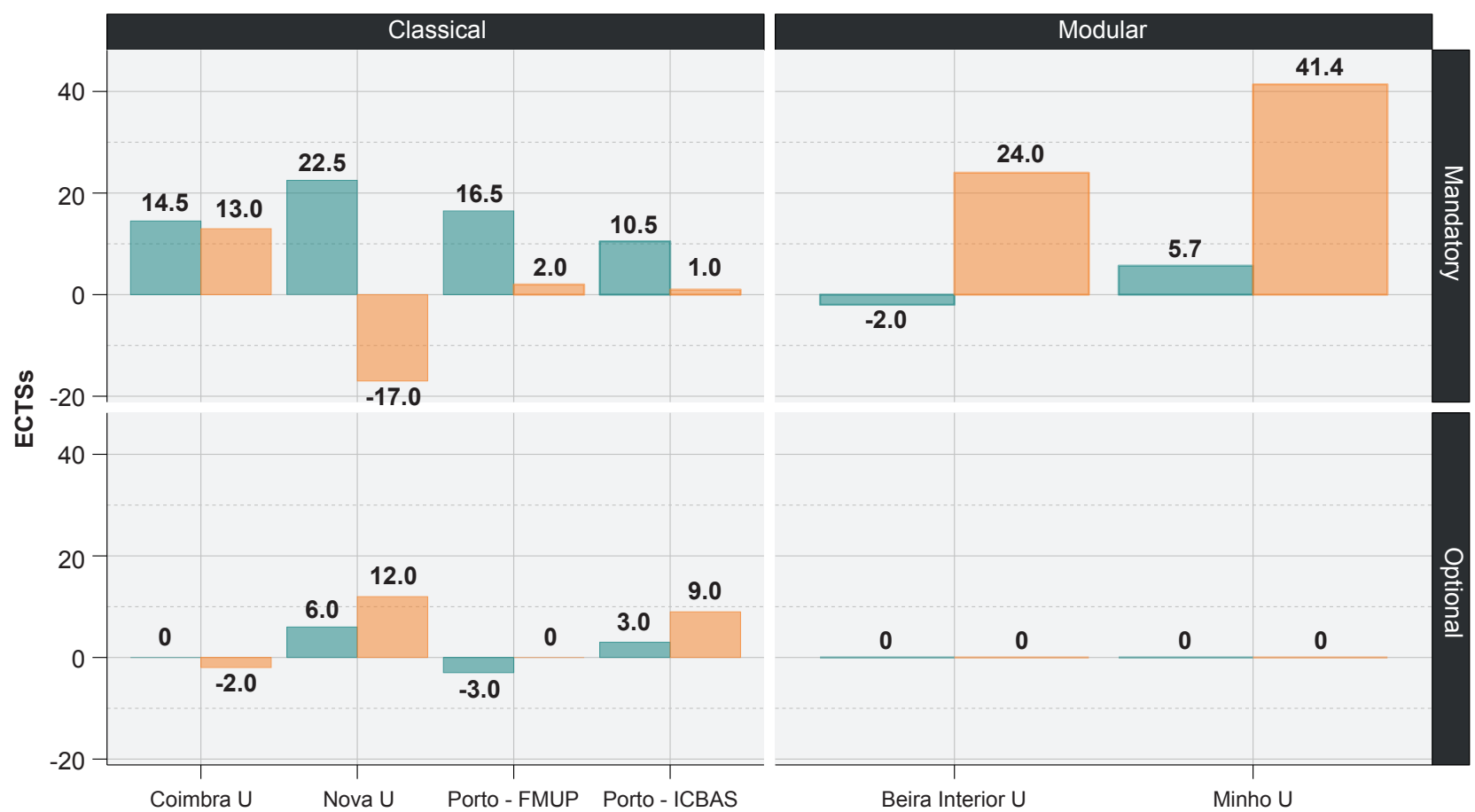

PMSs

Specific courses

Related courses

Figure 2 - Difference of Pediatrics teaching and Geriatrics teaching in classical and modular Portuguese Medical Schools (PMSs), by category.

ECTSs: European Credit Transfer and Accumulation System Credits.

Table 4 - Ratios between Pediatrics and Geriatrics teaching

\begin{tabular}{|c|c|c|c|c|c|}
\hline & \multirow{2}{*}{ PMS } & \multicolumn{2}{|c|}{ Mandatory } & \multicolumn{2}{|c|}{ Optional } \\
\hline & & Specific courses & Related courses & Specific courses & Related courses \\
\hline \multirow{4}{*}{$\begin{array}{l}\frac{U}{N} \\
\frac{D}{\sigma} \\
U\end{array}$} & Coimbra U & inf & 1.8 & 1.0 & 0.75 \\
\hline & Nova U & 6.6 & 0.7 & 3.0 & 2.0 \\
\hline & Porto - FMUP & 12 & 1.2 & - & $\mathrm{N} / \mathrm{A}$ \\
\hline & Porto - ICBAS & inf & 1.0 & inf & 4.0 \\
\hline \multirow{2}{*}{$\begin{array}{l}\frac{\bar{\pi}}{2} \\
\frac{2}{0} \\
\frac{0}{2}\end{array}$} & Beira Interior U & 0.75 & 5 & $\mathrm{~N} / \mathrm{A}$ & N/A \\
\hline & Minho U & inf & 4.9 & $\mathrm{~N} / \mathrm{A}$ & N/A \\
\hline
\end{tabular}

The trace (-) corresponds to zero. Inf: infinite value; N/A - Not applicable; PMS: Portuguese Medical Schools; U: University

we did not expect such high differences, especially in the classical group. A possible explanation to these results might be the fact that the modular curricula are more recent than the classical ones, appearing to be better adapted to the recent demographic tendency, exhibiting a more even distribution in the specific courses.

Nonetheless, when we look into the related courses, we observe the opposite, with higher differences in the modular PMSs. As explained in the methods section, the modular PMSs had courses that combined several subjects solely in one course, so it was expected that this group would have a higher amount of ECTSs in related courses than the PMSs of the classical teaching methodology.

Related courses accounted for most of the mandatory
ECTSs concerning Geriatrics and Pediatrics teaching, and were mainly attributable to broad courses such as Internal or Family Medicine. Traditionally, related courses have a higher ECTSs' count, not all of it being attributable solely to Geriatrics or Pediatrics. For that reason, these results may be overvalued. Taking into consideration that, according to our methodology, we based the classification of related courses on the presence of the keywords in the study plan, the existence of a more detailed plan description was of relevance. For example, Nova $U$ and Porto-ICBAS provided a comprehensive study plan which may help explain the higher attributed ECTSs.

It is also interesting to notice that, for each category of comparison, there was a single exception to the general rule 
(in which PT had a higher number of ECTSs attributed than GT). For the mandatory specific courses the exception was Beira Interior $U$ (as previously referred), for the mandatory related courses it was Nova $U$, in the optional specific courses the Porto-FMUP and in the optional related courses the Coimbra U.

Previous studies have shown that GT is widely heterogeneous, not only from country to country, but also within each country, varying in PMSs' structure and teaching methods. 3,15,16 With our results, we can say that Portugal is no exception to these terms since only three out of six PMSs offered mandatory specific geriatric courses. These results may be explained by the fact that each PMS has the autonomy to manage its study plans, which may confer some heterogeneity between PMSs, although they have to be approved by the National Accreditation Agency (A3ES Agência de Avaliação e Acreditação do Ensino Superior).

We identified four main limitations of this study: 1) The teaching methodology differs among PMSs, where four of them offer a classical program and the remaining ones offer a modular one. This fact may cause a bias when evaluating the study plans in an homogeneous manner, under or overvaluing the correspondent ECTSs; 2) There may exist some discrepancies between the PMSs' curricula and what is actually taught, obtaining overvalued results of PMSs' Geriatrics and Pediatrics Teaching; 3) Differences in the detail level of the courses program may influence the data results; 4) One of the PMSs refused to grant its curricula, disabling the opportunity to analyze all the PMSs that met the inclusion criteria.

\section{CONCLUSIONS}

Although geriatric and pediatric populations are epidemiologically comparable, the PMSs devote a larger share of the ECTSs to PT than GT. Overall we observed a larger availability of pediatric specific courses when compared with geriatric specific ones, warning us for the inadequacies in medical education.

Considering the contracting nature of the Portuguese age pyramid, and thereby the ever increasing geriatric population, we can conclude that the panorama of GT in Portugal is sub-optimal. This can be further observed in higher levels of education by the non-recognition of Geriatrics as a medical specialty.

With our study, we believe that we may raise awareness of the inadequacy of study plans presented by PMSs, pushing forward for a change in the amount of time and effort dedicated to Geriatrics. We suggest a re-evaluation of the teaching necessities taking into account the actual needs. Besides, efforts should be made to improve GT in order to better prepare future physicians for the population's needs. The suitability not only arguably will improve the population's quality of life but also the quality/efficiency of service.

\section{PROTECTION OF HUMANS AND ANIMALS}

The authors declare that the procedures were followed according to the regulations established by the Clinical Research and Ethics Committee and to the Helsinki Declaration of the World Medical Association.

\section{DATA CONFIDENTIALITY}

The authors declare having followed the protocols in use at their working center regarding patients' data publication.

\section{CONFLICTS OF INTEREST}

The authors declare that there are no conflicts of interest.

\section{FUNDING SOURCES}

No subsidies or grants contributed to this work.

8. Ordem dos Médicos [website]. [Accessed 2016 Sep 20]. Available at: https://www.ordemdosmedicos.pt/?lop=conteudo\&op=7f1de29e6da19d 22b51c68001e7e0e54.

9. Faculdade de Medicina - Universidade de Coimbra [website]. Plano de estudos; [Accessed 2016 Apr 20]. Available at: https://apps.uc.pt/ courses/PT/programme/5841/2016-2017?id_branch=16221.

10. Faculdade de Ciências Médicas - Universidade Nova de Lisboa [website]. Plano de estudos; [Accessed 2016 Apr 20]. Available at: http://www.fcm.unl.pt/main/alldoc/galeria_imagens/Regulamento_do_ MIM_2015-2016.pdf.

11. Faculdade de Medicina - Universidade do Porto [website]. Plano de estudos; [Accessed 2016 Apr 20]. Available at: https://sigarra.up.pt/ fmup/pt/cur_geral.cur_planos_estudos_view?pv_plano_id=3708\&pv_ ano_lectivo=2016\&pv_tipo_cur_sigla=MI.

12. Instituto de Ciências Biomédicas Abel Salazar - Universidade do Porto [website]. Plano de estudos; [Accessed 2016 Apr 20]. Available at: https://sigarra.up.pt/icbas/pt/cur_geral.cur_planos_estudos_view?pv_ plano_id=13402\&pv_ano_lectivo=2016\&pv_tipo_cur_sigla=MI\&pv_ origem $=$ CUR.

13. Faculdade de Ciências da Saúde - Universidade da Beira Interior [website]. Plano de estudos; [Accessed 2016 Apr 20]. Available at: http:// www.ubi.pt/PlanoDeEstudos/52.

14. Escola de Ciências da Saúde - Universidade do Minho [website]. Plano de estudos; [Accessed 2016 Apr 20]. Available at: https://www.med. 
uminho.pt/pt/Medicina/Paginas/Plano-Estudos.aspx.

15. Anderson MB, American Medical Colleges. A thematic summary of the geriatrics curricula at 40 US medical schools. Acad Med. 2004;79:S21326.
16. Bartram L, Crome P, McGrath A, Corrado OJ, Allen SC, Crome I. Survey of training in geriatric medicine in UK undergraduate medical schools. Age Ageing. 2006;35.5:533-5 